\title{
VEINTE AÑOS DE ESTUDIOS DE LINGÜÍSTICA
}

\author{
Dolores Azorín Fernández \\ Leonor Ruiz CARrillo
}

Hace veinte años salía a la luz el primer número de la revista Estudios de Lingüistica. Universidad de Alicante (ELUA). El tiempo transcurrido desde entonces ha dado la razón a quienes, supliendo con entusiasmo y no poco esfuerzo todo tipo de carencias, en el curso 1982-1983, apenas tres años después de haberse constituido como tal la actual Universidad de Alicante, se lanzaron a la aventura de editar unos Anales de Lingüística, siguiendo en ello el camino trazado por otras publicaciones periódicas ya consolidadas en el ámbito universitario.

El camino recorrido, no exento de escollos que en más de una ocasión hicieron zozobrar la empresa, se salda con un balance de logros que supera, a nuestro entender, al de los fracasos puntuales que se hayan podido producir. Entre los primeros, destaca la extensa nómina de colaboradores, en la que figuran destacadísimos investigadores que cubren la casi totalidad de las parcelas en que hoy se escinden las ciencias del lenguaje. Sin duda, es éste nuestro mejor patrimonio, responsable de que $E L U A$ cuente en la actualidad con un espacio propio entre las revistas universitarias de su especialidad.

No es menos importante, entre las metas alcanzadas, el volumen de intercambios que nuestra revista ha conseguido establecer con otras publicaciones nacionales y extranjeras y que ha servido de plataforma para dar a conocer las investigaciones de varias generaciones de profesores de distintas universidades españolas. De manera recíproca, el intercambio nos ha permitido enriquecer, con valiosos instrumentos, la hemeroteca de nuestra universidad, facilitando el acceso de alumnos y profesores a los avances que se han ido produciendo en el marco de las disciplinas lingüísticas.

Con motivo de este vigésimo aniversario, el consejo de redacción de Estudios de Lingüística ha creído oportuno aprovechar la efeméride para introducir algunas modificaciones tanto en el diseño de la página como en el de la cubierta de nuestra revista, a modo de compromiso con la modernidad y como símbolo del afán de progreso que debe guiar toda tarea colectiva de índole intelectual. A estos cambios que, a buen seguro, contribuirán a mejorar la imagen externa de nuestra publicación, se añade otro de mayor calado, como es la presencia de un Consejo asesor, integrado por especialistas de máximo nivel en su ámbito de investigación, que dotará a la revista de mayor respaldo científico.

Ante este nuevo ciclo que se abre con la publicación del número 17 de Estudios de Lingüistica, queremos reiterar el compromiso de nuestra revista con las ideas de independencia, calidad y apertura a todas las corrientes de la investigación que alentaron su aparición hace veinte años y han hecho posible su continuidad hasta hoy. 
Es el momento de recordar a las personas que, de manera absolutamente desinteresada, dedicaron muchas horas de su tiempo a las tareas que conlleva la gestión de una revista científica como Estudios de Lingüistica. Nuestro agradecimiento, pues, a todos los profesores que han formado parte del Consejo de redacción y a los especialistas que emitieron informes a instancias de aquél. De manera especial, queremos dejar patente la deuda contraída con los distintos coordinadores de $E L U A$, singularmente con los que llevaron sus riendas en la etapa fundacional: D. Tomás Albaladejo, D. Francisco Gimeno y D. Agustín Vera. De su trabajo aprendimos los que nos hemos venido ocupando posteriormente de este mismo cometido: D. José Luis Cifuentes, D. ${ }^{a}$ Ana Isabel Navarro, D. Juan Luis Jiménez, D. a Dolores Azorín,

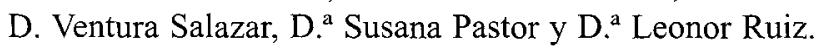

Alicante, 6 de diciembre de 2003 